\title{
POSSÍVEIS CONTRIBUIÇÕES DAS TEORIAS DA COGNIÇÃO CORPORIFICADA E MENTE ESTENDIDA NA APRENDIZAGEM E NA MÚSICA
}

\author{
Luciana Carolina Fernandes de Faria, Sheila Regiane Franceschini \\ Universidade do Oeste Paulista - UNOESTE. Licenciatura em Música. Presidente Prudente/SP. Email: \\ luciana.carolina@gmail.com
}

\section{RESUMO}

Este trabalho pretende tecer considerações sobre aprendizagem, com base em conceitos como cognição corporificada e mente estendida, e música, compreendida em suas diversas manifestações, enquanto escuta, aprendizagem, criação e interpretação, à luz dos mesmos conceitos. Por meio das ideias de pensadores como Francisco Varela, Humberto Maturana, Alva Noë e Andy Clark, é possível compreender que processo cognitivo não é apenas um processamento cerebral e que não pode ser separado da ação e da percepção. Tais teorias permitem uma reflexão sobre o papel do corpo na cognição e dos dispositivos aos quais o ser humano contemporâneo está acoplado. Assim, serão abordadas possíveis contribuições para a compreensão da aprendizagem e da música de uma forma humanizada, objetivando encontrar influências de tecnologias, que possibilitaram a compreensão da música não apenas como forma de expressão do ser humano, mas como meio para o seu próprio desenvolvimento.

Palavras-chave: Aprendizagem. Música. Cognição corporificada. Mente estendida.

\section{POSSIBLE CONTRIBUTIONS OF THEORIES OF EMBODIED COGNITION AND EXTENDED MIND IN LEARNING AND MUSIC}

\begin{abstract}
This work intends to make considerations about learning, based on concepts like embodied cognition and extended mind, and music, understood in its diverse manifestations, while listening, learning, creation and interpretation, in the light of the same concepts. Through the ideas of thinkers such as Francisco Varela, Humberto Maturana, Alva Noë and Andy Clark, it is possible to understand that cognitive process is not only a brain processing and can't be separated from action and perception. Such theories allow a reflection on the role of the body in cognition and the devices to which the contemporary human being is coupled. Thus, possible contributions will be addressed to the understanding of learning and music in a humanized way, aiming to find influences of technologies, which enabled the understanding of music not only as a form of expression of the human being, but as a means for its own development.
\end{abstract}

Keywords: Learning. Music. Cognition embodied. Extended mind. 


\section{INTRODUÇÃO}

Durante os últimos quatro séculos, a ciência cognitiva esteve firmada sobre o paradigma cartesiano, prevalecendo uma visão de mundo racionalista e mecanicista. Ainda como uma forte influência nas ciências, esta concepção pressupôs um mundo pré-determinado, independente do conhecimento que se possa ter dele, enfatizando a dualidade na natureza, com a separação entre corpo e mente, sujeito e objeto. Neste paradigma a cognição depende da análise e da fragmentação, de forma que para conhecer é preciso dividir o todo em partes. Estes conceitos afetaram a Educação, posicionando o aluno como um receptor passivo do conhecimento, em uma metodologia padronizada, cujo aprendizado é um processo de memorização de informações sem a preocupação de significação para o aluno. Portanto, o processo de desenvolvimento deste aluno se torna descorporificado e, assim, desumanizado.

Como alternativa a esta realidade, busca-se neste estudo bases epistemológicas que transcendam esta perspectiva dualista e descolada da experiência de mundo. A partir de um olhar fenomenológico, baseado nas teorias da cognição corporificada e da mente estendida, é possível compreender o processo de aprendizagem de uma forma mais humanizada, não apenas valorizando o aspecto racional, e sim a totalidade do ser, e que a cognição se dá pelas interações entre corpo e mundo, e não como resultado de um processamento cerebral. A paridade entre a importância dos processos cognitivos internos e externos sugere reflexões fundamentais na área da Educação e também na área da Música, pois tem como premissa prezar pela experiência e não apenas pela sua representação mental.

Destarte, este artigo tem como objetivo refletir sobre possíveis contribuições que as teorias da corporificação e da mente estendida podem proporcionar para ressignificar conceitos como aprendizagem e escuta.

\section{METODOLOGIA}

Para alcançar os objetivos propostos neste trabalho, foi realizada uma pesquisa bibliográfica que abordasse os conceitos em questão, culminando na argumentação em torno da aprendizagem e da música. Então, foram analisadas situações de relação entre aprendizagem e música a partir dos conceitos das teorias apresentadas. A partir dos resultados desta análise, foi possível identificar as transformações no meio educacional e na música, em virtude da mediação tecnológica e da quebra de paradigmas.

\section{RESULTADOS}

Nesta discussão, tomamos como base os estudos de Varela et al. (2003), quando se refere a cognição como dependente de um corpo em situação e de sua indissociabilidade da ação e da percepção.

\footnotetext{
Vamos explicar o que queremos dizer pela expressão ação incorporada. Usando o termo incorporada queremos chamar a atenção para dois pontos: primeiro, que a cognição depende dos tipos de experiência decorrentes de se ter um corpo com várias capacidades sensório-motoras, e segundo, que essas capacidades sensório-motoras individuais estão, elas mesmas, embutidas em um contexto biológico, psicológico e cultural mais abrangente. Utilizando o termo ação queremos enfatizar novamente que os processos sensoriais e motores - a percepção e a ação - são fundamentalmente inseparáveis na cognição vivida. De fato, os dois não estão apenas ligados contingencialmente nos indivíduos: eles também evoluíram juntos. (VARELA et al, 2003, p. 177)
}

Enquanto o modelo tradicional da cognição apresenta um sistema de processamento no cérebro, de um mundo pré-determinado e separado do sujeito, a cognição corporificada coloca um corpo em situação, que percebe, e ao perceber se faz e aprende. Segundo Alva Noë (2004) a percepção é uma habilidade corporal e uma forma de ação. "Percepção não é apenas o que nos 
acontece, ou em nós. É algo que nós fazemos." (NOË, 2004, p. 1, tradução nossa). Desta forma, a cognição se faz na interação com mundo, por meio da percepção e ação de um corpo situado.

Em outra abordagem fenomenológica, na teoria dos sistemas autopoiéticos de Maturana e Varela (2001) é possível perceber algumas convergências com esta concepção de cognição, pois, definindo o ser humano como um ser autopoiético, os autores defendem que a cognição é resultado da sua ação no meio ao qual está acoplado, e que este acoplamento (interação com o meio) e sua autoprodução (o que percebe e aprende) é condição sine qua non para a manutenção da sua vida.

Essa circularidade, esse encadeamento entre ação e experiência, essa inseparabilidade entre ser de uma maneira particular e como o mundo nos parece ser, nos diz que todo ato de conhecer faz surgir um mundo. [...] Tudo isso pode ser englobado no aforismo: todo fazer é um conhecer e todo conhecer é um fazer. (MATURANA; VARELA, 2001, p. 32, grifo dos autores).

Pensar a cognição como dependente de processamento, pelo cérebro, de representações mentais de um mundo externo é expressão do estruturalismo, de um dualismo corpo e mente. Compreender que, por meio da percepção e cognição o ser cria representações mentais de um mundo externo é aceitar que a mente está "dentro" da cabeça e a cognição se resume na descrição de um mundo externo, "fora" da cabeça. Antes disso, a fenomenologia enfatiza que a experiência do mundo é anterior à qualquer representação que se possa fazer dele. Como afirma Merleau-Ponty (2011, p. 5) "O mundo está ali antes de qualquer análise que eu possa fazer dele". Só se pode pensar sobre o mundo porque ele já lhe foi dado pela percepção. Assim, cognição é o que emerge da relação entre ser e mundo.

A cognição é incorporada quando é profundamente dependente das características do corpo físico do ser, ou seja, quando os aspectos de seu corpo, além de seu cérebro, desempenham um papel causal ou fisicamente constitutivo significativo no processo cognitivo. Geralmente, visões dominantes na filosofia da mente e na ciência cognitiva têm considerado o corpo como periférico para entender a natureza da mente e da cognição, o que é visto como um grave erro pelos defensores da ciência cognitiva corporificada, pois a natureza da dependência da cognição no corpo pode sugerir novas maneiras de conceituar e explorar a cognição.

A mente estendida é uma idéia no campo da filosofia da mente, que sustenta que o alcance da mente não precisa terminar nos limites da pele e do crânio. Ferramentas, instrumentos e outros adereços ambientais podem, sob certas condições, também contar como partes apropriadas de nossas mentes. A esta ideia são, frequentemente, associadas as teorias da cognição situada, distribuída e corporificada.

Clark e Chalmers (1998) apresentam a ideia de externalismo ativo, em que os objetos do ambiente funcionam como parte da mente. O argumento é de que a mente não está contida apenas dentro dos limites do crânio e se estende a objetos externos que desempenham um papel significativo no auxílio dos processos cognitivos. Assim, a mente e o ambiente atuam como um "sistema acoplado". Nestas situações, considera-se que o organismo humano está ligado a uma entidade externa, numa interação que permite pensar um sistema cognitivo por si só, onde todos os componentes desempenham papel causal ativo e controlam o comportamento, tal qual a cognição. Quando o componente, seja interno ou externo, recebe o mesmo tratamento, em importância, uma vez que em ambos os casos o processo cognitivo ocorre em similaridade, chamamos de Princípio da Paridade.

Se, ao confrontarmos alguma tarefa, uma parte do mundo funciona como um processo que, se fosse feito na cabeça, não hesitaríamos em reconhecer como parte do processo cognitivo, então essa parte do mundo é (então reivindicamos) parte do processo cognitivo. Processos cognitivos não estão (todos) na cabeça! (CLARK; CHALMERS, 1998, p. 8 , tradução nossa). 
Durante o tempo de vida de um organismo o seu aprendizado pode ter moldado o sistema cognitivo de acordo com as extensões cognitivas que o cercam enquanto aprendem. A linguagem é um exemplo disso, assim como outros recursos tecnológicos cotidianamente presentes e utilizados para diversas finalidades, no âmbito da aprendizagem. O cérebro se desenvolve de forma a complementar as estruturas externas, desempenhando seu papel num sistema unificado.

Outro exemplo pode ser a linguagem, que parece ser um meio central pelo qual os processos cognitivos são estendidos ao mundo. Pense em um grupo de pessoas debatendo em torno de uma mesa, ou um filósofo que pensa melhor escrevendo, desenvolvendo suas idéias à medida que elas acontecem. Pode ser que a linguagem tenha evoluído, em parte, para possibilitar tais extensões de nossos recursos cognitivos dentro de sistemas ativamente acoplados. (CLARK; CHALMERS, 1998, p. 12, tradução nossa).

De acordo com as ideias de Clark, temos ainda na linguagem uma maneira de estender para o mundo os processos cognitivos, através de sistemas acoplados ativamente.

\section{DISCUSSÕES}

Contemplando as teorias expostas, é possível verificar que tais conceitos inauguram profundas reflexões na Educação e na Música. Destacamos aqui quatro pontos de reflexão sobre educação a partir de uma abordagem corporificada e cinco reflexões sobre a experiência de escuta musical.

O primeiro ponto a se refletir é compreender o aprendizado não é apenas um processamento de informação percebidas em um meio pré-determinado, mas sim o resultado de uma dinâmica relação entre o ser e o mundo. O aluno passa de uma condição passiva para uma posição ativa em seu processo de desenvolvimento humano. Sem o envolvimento e a ação efetiva do aluno, não pode haver aprendizado. Desta forma, aprender é mais do que assistir passivamente as aulas e memorizar informações sem relacioná-las com a sua própria história. Aprender é dar sentido às coisas.

Em suma: se a vida é um processo de conhecimento, os seres vivos constroem esse conhecimento não a partir de uma atitude passiva e sim pela interação. Aprendem vivendo e vivem aprendendo. Essa posição, como já vimos é estranha a quase tudo o que nos chega por meio da educação formal. (MATURANA; VARELA, 2001, p 12)

Como segunda reflexão considera-se que se toda ação e percepção estão atadas à cognição, toda prática produz conhecimento e novos hábitos, assim, o aluno não aprende somente no ambiente escolar e o conhecimento que ele partilha com seu professor e colegas é apenas uma das inúmeras possibilidades de interações que ele tem durante toda sua vida. Assim, o professor não é mais o centro do processo cognitivo, nem é o detentor de todo conhecimento e único responsável em transmitir informações. Melhor seria considerar seu papel mediador de conhecimento.

Como terceiro ponto de reflexão ressalta-se a ressignificação do corpo no processo de aprender. Ao reconhecer o corpo como algo a mais que apenas um recipiente para o cérebro, mas o meio fundamental com o qual o ser humano age no mundo e se autoproduz, é possível compreende-lo em sua integralidade, como entidade holística e não fragmentável. Desta forma, a partir desta concepção, valoriza-se o aluno em sua totalidade: cognitivo, emocional, motor, social, e entende-se que todas estas dimensões são interdependentes e indissociáveis.

Como quarto ponto de reflexão na aprendizagem destaca-se como o acoplamento entre os seres humanos e as novas tecnologias influencia a forma de pensar, perceber, significar e agir no mundo. Desta forma, a escola precisa considerar este acoplamento e utilizar as novas tecnologias em sua práxis educacional.

Tecnologias fundamentais são aquelas que provocam mutações nas linguagens humanas. Trata-se, portanto, de tecnologias de linguagem que hoje passamos a chamar de mídias. 
São fundamentais porque mudanças nas linguagens produzem mudanças na própria natureza humana, nos nossos modos de perceber, sentir, adaptar-nos, pensar, agir, habitar e compreender o mundo em que vivemos. Diante disso, o que realmente importa não é tanto o que fazemos com as tecnologias, mas, mais propriamente, o que elas fazem conosco. (SANTAELLA apud FERRARI, 2016, p. 11)

Além disso, é possível identificar contribuições destas teorias também na área da música, um campo de conhecimento que acompanha o homem em seu desenvolvimento histórico, como evidências de um corpo que sente, percebe, cria e produz som, estabelecendo significados e, até mesmo, impondo regras. Assim, é interessante notar como o ser humano tem sua vida permeada pelos sons e pode, por meio da escuta, construir uma noção de mundo. Cabe considerar o importante papel da cultura, enquanto espaço de construção de conhecimentos, hábitos, valores, crenças, normas e manifestações, da qual a música é partícipe, porque é expressão e comunicação humana.

Considerando-se que todo fenômeno de cultura só funciona culturalmente porque é também um fenômeno de comunicação, e considerando-se que esses fenômenos só comunicam porque se estruturam como linguagem, pode-se concluir que todo e qualquer fato cultural, toda e qualquer atividade ou prática social constituem-se como práticas significantes, isto é, práticas de produção de linguagem e de sentido. (SANTAELLA, 2007, p. 2)

Na música ancestral temos uma atividade utilitária, com função ritual, ou ainda com função de comunicação, no cotidiano, sendo presente antes mesmo do desenvolvimento da linguagem falada. $O$ desenvolvimento diferenciado do aparelho fonador humano permitiu, posteriormente, 0 desenvolvimento da fala e impactos nos processos cognitivos. Assim, o canto é anterior à fala e juntamente com esta promovem o desenvolvimento humano. Ao longo da história, a música foi aliando-se a finalidades estéticas, políticas, ideológicas e/ou sociais, assumindo importância histórica, formativa, técnica, como um retrato do tempo vivido: a música reflete o homem de seu tempo, por meio das diversas formas, gêneros e estilos de produção musicais, como um elo inevitável entre o ser ancestral e o ser contemporâneo.

Dessa forma, como primeiro ponto de reflexão, numa perspectiva em que a percepção e ação musicais produzam cognição, o fazer musical já é a corporificação, independentemente de qual sistema composicional a que esteja submetido. A música é a própria experiência sonora, não importa em que estágio ou período histórico se encontre o agente. Seu corpo em ação, no contexto sonoro, em contato com o mundo percebido, é música.

Como segundo ponto de reflexão, entende-se que quando o indivíduo toca seu instrumento, ou a cria por meio de recursos eletrônicos, relaciona-se com ele como se fosse uma extensão de seu corpo; quando aquilo que realiza com o suporte sonoro é uma continuidade do que acontece dentro de si (ainda que numa abordagem dualista), podemos considerar a música resultado deste acoplamento. Assim como a relação que se estabelece entre as pessoas e seus aparelhos celulares, como parte de sua memória e conexão com um mundo, com uma inteligência coletiva e distribuída, pode a música assumir esse papel, tendo em vista que ela também é conexão consigo, com o mundo e com o outro.

Em terceiro lugar, a escuta é o primeiro fazer musical efetivo que se expande por meio do gesto e da ação musical. E quando este fazer musical se torna consciente, promove no indivíduo a expansão das capacidades cognitivas, expressivas, afetivas e de potencial para a empatia e emoção. Neste contexto, Marc Leman apresenta o conceito da cognição musical incorporada:

O paradigma da cognição da música incorporada é baseado em vários conceitos, relacionados a: (i) o corpo como mediador, (ii) o repertório de ação / gesto, (iii) o acoplamento da percepção de ação e (iv) a ligação com o subjetivo experiências, tais como intenções, expressões, empatia e emoções. (LEMAN, 2012, p. 5, tradução nossa) 
Dessa forma, pode-se observar a importância da música nos processos cognitivos, justificados pelos conceitos mencionados, como uma prática inerente e essencial à vida, fruto da experiência que repercute em maneiras de ser, estar e agir no mundo.

Compreende-se aqui, então, que a escuta, enquanto ação de um corpo situado, é uma experiência vital para o ser humano. Desta afirmação emerge uma quarta reflexão que ressignifica a educação musical, deixando de ser um privilégio de poucos nascidos com o talento para a música e, também, de ser apenas um estudo técnico de um instrumento musical. A escuta enquanto vital para o ser humano consagra uma educação musical necessária a todos, como forma de potencializar sua ação no mundo e, consequentemente, seu desenvolvimento enquanto ser.

Nesta ação da escuta identifica-se a indissolução de percepção-ação-cognição e emerge a quinta e última reflexão abordada neste estudo. Por vezes na história das relações entre a escuta e o ser humano a ciência esteve ocupada em investigar o som, como seu objeto concreto. Contudo, ao atribuir toda a importância para o som, assume-se um olhar dualista do mundo: o som como algo externo ao sujeito, em uma experiência esvaziada, sem um corpo ou um lugar para percebêlo. Afinal, nesta perspectiva da cognição corporificada, o som é como uma descrição da escuta, a representação da experiência de escutar. Se se entende som sem considerar a escuta, não há mais o mundo, mas sim a representação dele. Assim, som é o nome atribuído à experiência da escuta do ser interagindo com o mundo.

\section{CONCLUSÃO}

As teorias da cognição corporificada e da mente estendida, assim como outras concepções, levam à reflexão de que a aprendizagem não pode ser passiva, não é um processo puramente racional, nem descorporificado. A cognição está ligada à percepção e à ação, de forma que uma não acontece sem a outra, e, assim, aprender é uma ação do ser situado no mundo. Este ser não pode ser fragmentado nem negar parte de si mesmo, de modo que suas ações no mundo envolvem a totalidade de suas dimensões: cognitiva, motora, emocional, psicológica, social. Além disso, é preciso também considerar que o avanço tecnológico e a expressiva presença dos dispositivos digitais nas diversas tarefas no cotidiano dos seres contemporâneos causam uma mudança na forma de perceber, agir, pensar e se relacionar com o mundo e com os outros seres.

Superar os vestígios que o dualismo deixou na ciência e no entendimento de mundo ainda é um desafio, pois refutar este padrão de pensamento e buscar novas bases filosóficas para as reflexões nas diversas áreas exige um abandono do status quo. A fenomenologia, de uma forma geral, sugere um retorno à experiência, colocar como foco da investigação científica não o objeto e nem o sujeito, mas sim a relação entre eles. A partir da teoria de um corpo situado, que se faz em seu encontro com o mundo, compreende-se que a cognição não acontece no mundo externo nem dentro da cabeça, mas sim da dinâmica relacional entre ser e mundo.

\section{REFERÊNCIAS}

CLARK, Andy; CHALMERS, David. The extended mind. In: Analysis, Vol. 58, No. 1 (Jan), pp. 7-19, 1998. https://doi.org/10.1093/analys/58.1.7

FERRARI, Pollyana. Comunicação digital na era da participação. Porto Alegre: Editora Fi, 2016.

LEMAN, Marc. Musical gestures and embodied cognition. In: Actes des Journées d'Informatique Musicale (JIM 2012), Mons, Belgique, 9-11 mai 2012, p. 5-7.

MATURANA, Humberto; VARELA, Francisco; A árvore do conhecimento: as bases biológicas da compreensão humana. São Paulo: Palas Athena, 2001. 
MERLEAU-PONTY, M. Fenomenologia da Percepção. Trad. Carlos Alberto Ribeiro de Moura. São Paulo: Martins Fontes, 2011.

NOË, Alva. Action in perception. Cambridge, MA: MIT Press, 2004.

SANTAELLA, Lucia. O que é semiótica. São Paulo: Brasiliense, 2007.

VARELA, Francisco THOMPSON, Evan; ROSCH, Eleanor. A mente incorporada: ciências cognitivas e experiência humana. Porto Alegre: Artmed, 2003. 